

\title{
Radioactive ion beams at Spiral
}

A.C.C. Villari, J.C. Angélique, Bertram Blank, F. Clapier, J.M. Deligne, M. Ducourtieux, P. Foury, A. Joubert, N. Lecesne, A. Lepine, et al.

\section{To cite this version:}

A.C.C. Villari, J.C. Angélique, Bertram Blank, F. Clapier, J.M. Deligne, et al.. Radioactive ion beams at Spiral. Nouvelles de Ganil, 1994, 53, pp.3-9. in2p3-00013072

HAL Id: in2p3-00013072

https://hal.in2p3.fr/in2p3-00013072

Submitted on 28 Jan 2014

HAL is a multi-disciplinary open access archive for the deposit and dissemination of scientific research documents, whether they are published or not. The documents may come from teaching and research institutions in France or abroad, or from public or private research centers.
L'archive ouverte pluridisciplinaire HAL, est destinée au dépôt et à la diffusion de documents scientifiques de niveau recherche, publiés ou non, émanant des établissements d'enseignement et de recherche français ou étrangers, des laboratoires publics ou privés. 


\title{
Radioactive ion beams at SPIRAL *
}

\author{
A.C.C. Villari1, J.C. Angelique ${ }^{2}$, B. Blank³, F. Clapier4, J.M. Deligne1, \\ 1. GANIL, B.P. 5027, 14021 Caen Cedex, France \\ 2. LPC-ISMRa, Bld. Marechal Juin, 14050 Caen, France \\ 3. CENBG, B.P. 120, 33175 Gradignan Cedex, France \\ 4. IPN, 91406, Orsay Cedex, France \\ 5. IFUSP, C.P. 20516, 01498 São Paulo S.P., Brasil \\ 6. CSNSM, Bat 104-108, 91406 Orsay, France
} M. Ducourtieux ${ }^{4}$, P. Foury ${ }^{1}$, A. Joubert ${ }^{1}$, N. Lecesne1, A. Lépine ${ }^{5}$, R. Leroy ${ }^{1}$, M. Lewitowicz' ${ }^{1}$, C.F. Liang6, J. Mandin ${ }^{1}$, C. Marry1, L. Maunoury1, J. Mercier1, J. Obert ${ }^{4}$, N.A. Orr ${ }^{2}$, J.Y. Pacquet ${ }^{1}$, P. Paris 6 , J.C. Potier ${ }^{4}$, J. Proust ${ }^{4}$, J.C. Putaux 4 , E. Robert ${ }^{1}$, M.G. Saint-Laurent ${ }^{1}$, P. Sortais ${ }^{1}$, M. Lieuvin ${ }^{1}$ and the SPIRAL group.

The radioactive ion beam facility SPIRAL, presently under construction, will be based on the very high intensity heavy-ion beams (96A MeV at $6 \mathrm{~kW}$ from He to Ar) at GANIL, France. The facility will produce radioactive ion beams using the ISOL method and a permanent magnet ECRIS which will allow for the production of multiple charged radioactive ions. The beam will be accelerated by a $K=265$ compact cyclotron and delivered into the existing experimental areas. The first tests for the production of radioactive ion beams has been undertaken with the test bench separator SIRa. A description of the facility, including the first results for the production of radioactive ion beams and perspectives are given.

\section{INTRODUCTION}

The study of the properties of the atomic nucleus far from the valley of stability is an old and passionate subject of research. The pioneering efforts of ISOLDE [1] at CERN, followed by other equally important centres based on the so-called Isotopic Separation On-Line (ISOL) technique, have contributed much to our present knowledge of the atomic nucleus far from stability.

Recently, an important breakthrough in the study of the fundamental properties of these nuclei came about when Symons and collaborators [2] demonstrated the usefulness of heavy-ion beams for the production of neutron-rich nuclei. Quickly following on from this development the first results of experiments using fast radioactive ion beams (RIB) appeared. For example, the first measurements of the interaction cross sections for light nuclei, made at the BEVALAC, USA by Tanihata and collaborators [3], provided the first evidence for the existence of an unexpected halo for the nucleus ${ }^{11} \mathrm{Li}$. From the first experiments in 1979, projectile fragmentation has also been used at GANIL- 
France, GSI-Germany, MSU-USA and RIKEN-Japan to produce and study reactions induced by radioactive beams. Separators have been built at these centres in order to maximise the RIB production and purity. All these facilities have in common the fact that RIBs are produced by projectile fragmentation at energies between $70 \mathrm{~A}$ and $2000 \mathrm{~A} \mathrm{MeV}$. It turns out from the principle of production and separation using a spectrograph that the optimum efficiency of the process is reached when the RIB has a velocity similar to that of the primary beam [4]. The production process, however, does imply losses in intensity and/or quality of the secondary beam, which become increasingly important as the beam is slowed down. From this point of view, the study of secondary beam reactions at low energies using intense RIBs is at present very difficult.

The SPIRAL facility, based on the ISOL method will provide for production and separation of RIBs, with subsequent acceleration by a $\mathrm{K}=265$ cyclotron to energies between $2 \mathrm{~A}$ and $25 \mathrm{~A} \mathrm{MeV}$, thus opening up the study of nuclear reactions around the Coulomb barrier to radioactive ion beams.

It should be noted that a similar facility exists at Louvain-la-Neuve, Belgium [5], which uses a $30 \mathrm{MeV}(200 \mu \mathrm{A})$ proton beam to produce RIBs and accelerates them with a $K=110$ cyclotron. This facility, due largely to the energy of the proton beam, is well suited to the production of RIBs near stability. A new post-accelerator dedicated to nuclear astrophysics is now under construction.

In the following sections we describe the projected facility (section 2) and the first results (section 3 ) obtained for the target-ion source system tested recently at the SIRa [6] separator. In section 4 a summary is provided.

\section{SPIRAL OVERVIEW}

Figure 1 shows a schematic plan of the GANIL building and the SPIRAL project.

\subsection{The improvement of beam intensity}

Today GANIL produces beams with intensities reaching $6 \times 10^{9}$ to $2 \times 10^{12}$ pps for ions from ${ }^{238} \mathrm{U}$ to ${ }^{12} \mathrm{C}$ at energies from $24 \mathrm{~A}$ to $96 \mathrm{~A} \mathrm{MeV}$. The combination of the new ECR4 source operating at $14.5 \mathrm{GHz}$ and an injection stage at $100 \mathrm{kV}$, has improved the intensity of the beam up to the second cyclotron CSS2 to $2 \times 10^{13}$ pps for ions up to ${ }^{40} \mathrm{Ar}$ and increased significantly the intensity of the heavier ones. This high intensity beam will be transported safely through the second cyclotron after the installation of a rebuncher (R2) in the line between the two main cyclotrons. This rebuncher is necessary in order to increase the transmission inside CSS2, which will be of the order of $98 \%$ after the installation of R2. The improvement of the primary beam intensity as well as the possibility of acceleration of lighter ions down to ${ }^{3} \mathrm{He}$ is of paramount importance for the SPIRAL project, as the full intensity and variety of primary beams will be used for the production of RIB. 


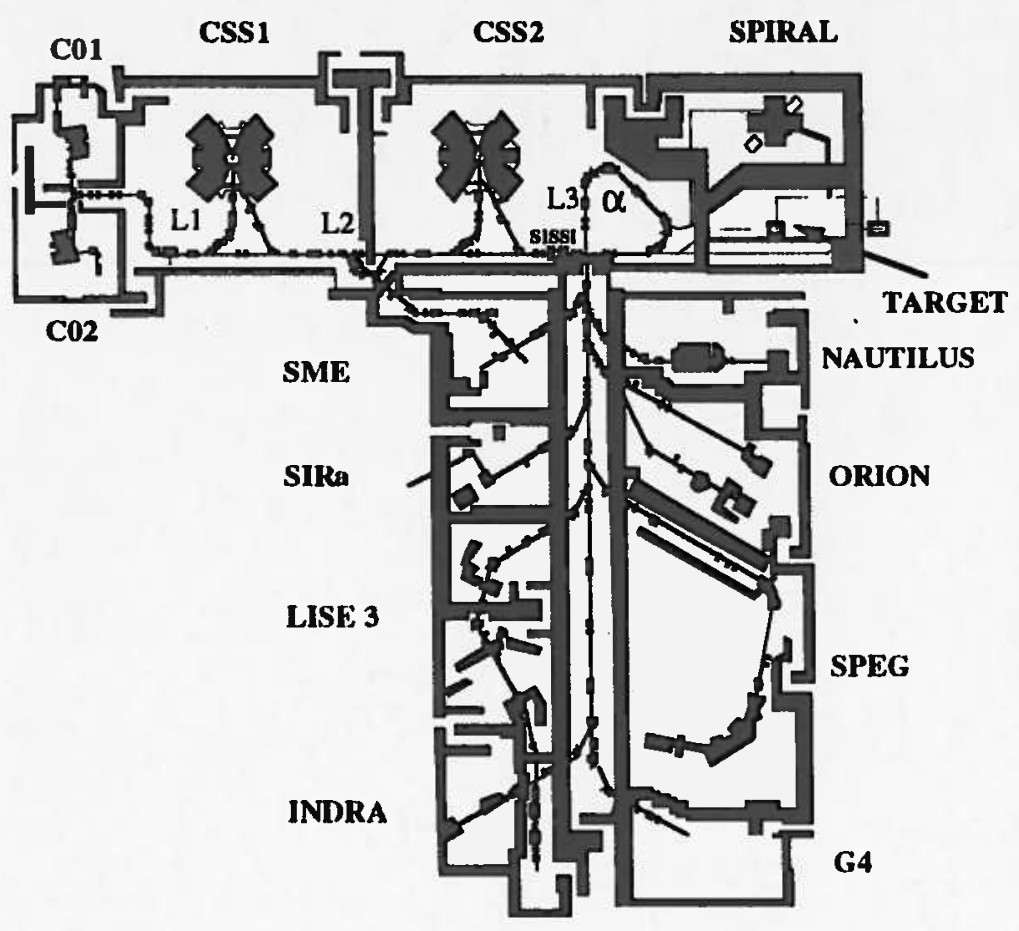

Figure 1.

Schematic view of GANIL and the SPIRAL project.

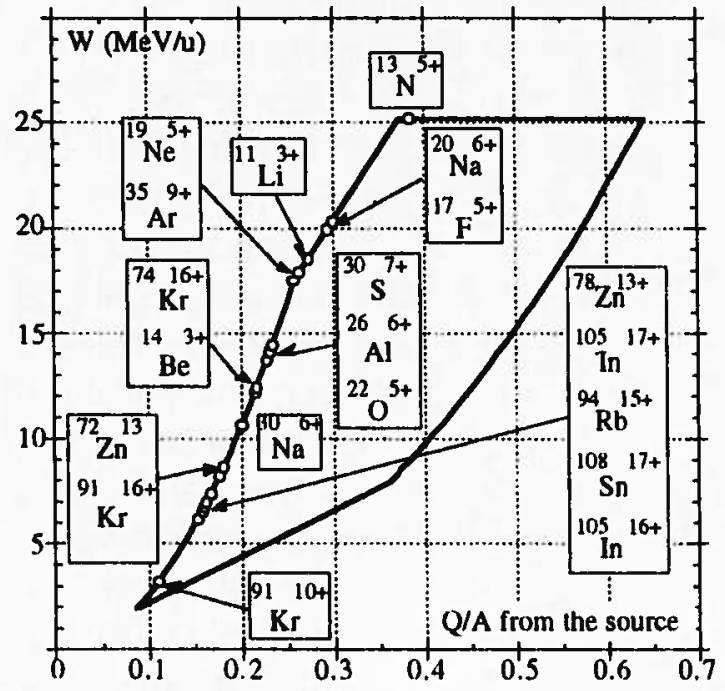

Figure 2.

Energy range of the CIME cyclotron

\subsection{Production of RIB}

The primary heavy-ion beam accelerated by the GANIL cyclotrons will bombard a production target located in a well shielded area beneath ground level in the machine building (see Figure 1.). The radioactive atoms produced by nuclear reactions will be released from the target, which will be at high temperature $(\sim 2300 \mathrm{~K})$, and will pass through a transfer tube into an ECRIS (Electron cyclotron resonance ion source). The radioactive atoms will then be ionised up to charge states corresponding to the ratio $\mathrm{q} / \mathrm{m}$ from 0.09 to 0.40 . After extraction from the 
ECRIS, the low energy RIB (acceleration voltage around 20kV) will be selected by a relatively low resolution separator $\left(\Delta \mathrm{m} / \mathrm{m}=4 \times 10^{-3}\right)$ and injected into the new $\mathrm{K}=265(\mathrm{~B} p=2.344 \mathrm{Tm})$ compact cyclotron $\mathrm{CIME}$. The corresponding energy range is given in figure 2. After acceleration, the RIB will be selected in magnetic rigidity by the modified $\alpha$-shaped spectrometer of GANIL and directed to the existing experimental areas. The separation between isobars will be performed for the most part by the cyclotron itself - which is a good spectrometer for fast ions [7] with a resolution of $\Delta \mathrm{m} / \mathrm{m} \leq 5 \times 10^{-4}$. Additional separation can be achieved by placing a stripper foil in the dispersive focal plane of the spectrometer or even a degrader. In the latter case, however, significant losses in RIB intensity will occur.

The new facility will be operational in 1998. During this year, tests of production and acceleration of RIBs will be made. Experiments are planned to be programmed for the end of 1998.

\section{RIB PRODUCTION, FIRST RESULTS AND PERSPECTIVE}

Classically in the ISOL technique a proton or a light-ion beam is accelerated to a high energy and bombards a thick target producing radioactive nuclei by spallation reactions, fragmentation of the target and/or induced fission. Other reaction mechanisms, however, come into play with heavy-ions. In particular, projectile fragmentation is the process of most importance. In all cases, the fragments are stopped in the target which is heated to a high temperature (1800K to $2300 \mathrm{~K}$ ) to facilitate the migration of the radioactive atoms to the surface. Usually the target is located at a short distance from the ion source and the radioactive atoms effuse via a transfer tube to the plasma region where they are ionised and then accelerated. However, given the relatively short range of heavy ions (typically they stop in the production target) one could imagine employing very small targets or even locating the target itself inside the ion source. Such a configuration would thus eliminate the losses due to sticking of radioactive atoms in the transfer tube - a major source of losses in systems presently in use. As the atoms are ionised and accelerated in a manner identical to that for stable beams, the resulting radioactive beams have good dynamical and optical characteristics when compared with projectile fragmentation, and an energy which may be precisely adjusted. The originality of the GANIL project lies in the use of an extended range of heavy-ions, up to the maximum energies available at GANIL (e.g.. 96A MeV for ${ }^{36} \mathrm{Ar}$ ). Such an approach differs from the proton (or light-ion) beam technique in that the projectile rather than the target is varied in order to produce the different radioactive species, thereby allowing one to use the most resilient and efficient production target for most of cases.

The results we present have been obtained using a classical target-ion source test system based on the ISOLDE type, i.e., with an external carbon target inside a tantalum tube, linked with the ion source by a $60 \mathrm{~cm}$ long tantalum plus copper 
transfer tube. These results demonstrate the order of magnitude of the beam intensities which can be reached by SPIRAL for noble gas beams.

The carbon target has been chosen due to its excellent release properties, low atomic number and high sublimation temperature. The carbon was furnished by Carbonne Lorraine, France (grade 2318) with a grain size of $4 \mu \mathrm{m}$ and $8 \%$ open porosity. This grain micro structure is well known as having fast release properties [8]. Another important characteristic of using a low Z element as a target is based on the physics of the production mechanism. The total production yield is a product of the production cross section times the number of incident particles per second and the number of scattering particles in the target. The cross section for projectile fragmentation increases with the size of the colliding system, however, this effect is compensated for by the longer range of the incident beam in a low- $Z$ target, i.e., the production yield is higher for lighter targets.

The ion source used during the tests is the Caprice-type ECR3 [9]. The entire system has been mounted at the new RIB on-line separator SIRa. The overall efficiency of the system, including SIRa, has been measured by implanting a known rate of $18 \mathrm{Ne}$ ions produced by projectile fragmentation of a $20 \mathrm{Ne}$ primary beam. The secondary $18 \mathrm{Ne}$ beam was selected and purified by the $\alpha$-shaped spectrometer and its rate determined by a Si detector located in front of the target of SIRa. The ${ }^{18 \mathrm{Ne}}$ released by the target at high temperature (between 1500 and $2100 \mathrm{~K}$ ) effused through the ECRIS, was ionised, extracted, selected by the separator and implanted in a plastic tape located downstream of SIRa. The $\gamma$-rays emitted by the decay of ${ }^{18} \mathrm{Ne}$ were detected using a Ge detector located in close proximity to the tape. The overall efficiency measured in this case for $18 \mathrm{Ne}$ for the charge state $5+$ was $3 \%$. Using a calibrated leak of ${ }^{22} \mathrm{Ne}$ gas which passed through the carbon target, we could unfold the efficiencies of each part of the separator. We extracted the time dependent part of the efficiency, which is the product of the diffusion and effusion efficiencies, from the time independent part which comprises the ionisation and transport efficiencies. The ion source efficiency can be described as the product between an ionisation and a delay efficiency, where the latter represents the time spent by an atom inside the source before being extracted. For noble gases with $\mathrm{T}_{1 / 2}>100 \mathrm{~ms}$, the sticking time on the walls is negligible and the confinement time is much smaller then the life time of the radioactive element. In this case the ion source efficiency can be assumed to be the same for stable and radioactive atoms. The different efficiencies are the following:

a) Product of diffusion and effusion efficiencies at $T_{\text {target }}=2000 \mathrm{~K}$ for ${ }^{18} \mathrm{Ne}: 45 \%$;

b) Efficiency of ionisation in the ECR for ${ }^{18} \mathrm{Ne}(5+): 20 \%$;

c) Transport efficiency of the SIRa separator: $36 \%$.

The performance of the ECRIS for a radioactive atom is the same as for a stable one. It has been tested on-line with an intense ${ }^{20} \mathrm{Ne}$ beam bombarding the target. 
The charge state distribution for ${ }^{18} \mathrm{Ne},{ }^{19} \mathrm{Ne}$ and ${ }^{22} \mathrm{Ne}$ are equivalent (see figure 3 ), demonstrating that the performance of the ECRIS is unaffected by the presence of the primary beam.

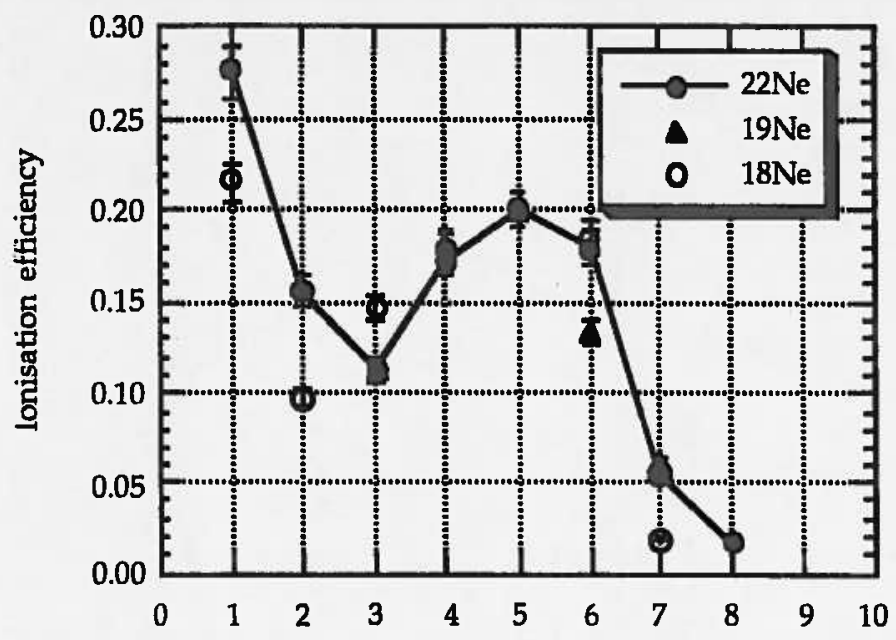

Figure 3.

Charge state distribution for Ne isotopes

The production yields of RIBs have been measured for a certain number of noble gases, where we expect to have good performance of the test system considering the effusion and ionisation efficiencies. The yields at the end of the separator, i.e., after diffusion, effusion, ionisation and transport, are presented in table 1. These yields were obtained using ${ }^{13} \mathrm{C},{ }^{20} \mathrm{Ne},{ }^{36} \mathrm{Ar}$ and ${ }^{78} \mathrm{Kr}$ primary beams at the maximum energies and intensities presently available at GANIL. We present also a projection to RIB intensity supposing a total beam power of $6 \mathrm{~kW}$ and a transmission of $50 \%$ inside the CIME cyclotron. The poor transport efficiency of the SIRa separator will be greatly improved for the separator to be incorporated in SPIRAL. This will enhance the final intensity of the beam by a factor of at least two. The full test system is being redesigned, in particular with a view to minimising the distances between target and the ion source. The latter can significantly augment the final SPIRAL beam intensities, in particular for short lived nuclei. The first SPIRAL ion source has been inspired by the full permanent magnet NANOGAN ion source [10] which is very compact and easy to maintain. Finally, other target materials will be tested in the near future.

\section{CONCLUSIONS}

We have presented a description of the SPIRAL facility and the first results for production of radioactive ion beams using a test production system in the new SIRa separator at GANIL. The results obtained for the charge state distribution of the ion source shows that the ECRIS works on-line in a separator with the same performance as off-line, using a carbon target and for radioactive noble gases with life times greater then $100 \mathrm{~ms}$. The first results obtained with the test system show 
reasonably good performances for production of RIBs of noble gases. The next generation target-ion source system will include a very compact, full permanen magnet ECRIS coupled to an external target in close proximity to the ion source. This new system will be operational at the end of 1995 and will be tested at SIRa in 1996. For condensable elements, a test system using an internal target (inside the ECRIS itself) will be available at the begining of 1995 .

Table 1. Measured yields with present GANIL intensities; with projections for $1 \mathrm{p} \mu \mathrm{A}$ of primary beam; and $6 \mathrm{~kW}$ of maximum incident beam power supposing a transmission of $50 \%$ inside the cyclotron CIME.

\begin{tabular}{|c|c|c|c|c|}
\hline $\begin{array}{l}\text { RIB (charge state) } \\
\text { and life time }\end{array}$ & primary beam & $\begin{array}{l}\text { Yield (pps) with } \\
\text { present intensities }\end{array}$ & $\begin{array}{l}\text { Yield(pps) for } \\
1 \mathrm{p} \mu \mathrm{A} \text { beam }\end{array}$ & $\begin{array}{l}\text { projected SPIRAL } \\
\text { intensities }\end{array}$ \\
\hline${ }^{77} \mathrm{Kr}(10+) 74.4 \mathrm{~m}$ & \multirow{6}{*}{$\begin{array}{c}{ }^{78} \mathrm{Kr}, 73 \mathrm{~A} \mathrm{MeV} \\
35 \mathrm{pnA} \\
\left(2.2 \times 10^{11} \mathrm{pps}\right)\end{array}$} & $6.1 \times 10^{6}$ & $1.7 \times 10^{8}$ & $9.2 \times 10^{7}$ \\
\hline $76 \mathrm{Kr}(10+) 14.8 \mathrm{~h}$ & & $3.6 \times 10^{6}$ & $1.0 \times 10^{8}$ & $5.3 \times 10^{7}$ \\
\hline $75 \mathrm{Kr}(10+) 4.3 \mathrm{~m}$ & & $1.8 \times 10^{5}$ & $5.1 \times 10^{6}$ & $2.7 \times 10^{6}$ \\
\hline${ }^{74} \mathrm{Kr}(9+) 11.5 \mathrm{~m}$ & & $7.0 \times 10^{4}$ & $2.0 \times 10^{6}$ & $1.1 \times 10^{6}$ \\
\hline $73 \mathrm{Kr}(9+) 27.0 \mathrm{~s}$ & & $2.5 \times 10^{3}$ & $7.1 \times 10^{4}$ & $3.8 \times 10^{4}$ \\
\hline $72 \mathrm{Kr}(9+) 17.2 \mathrm{~s}$ & & $2.6 \times 10^{2}$ & $7.4 \times 10^{3}$ & $3.9 \times 10^{3}$ \\
\hline $35 \mathrm{Ar}(8+) 1.77 \mathrm{~s}$ & \multirow{4}{*}{$\begin{array}{c}{ }^{36} \mathrm{Ar}, 96 \mathrm{~A} \mathrm{MeV} \\
115 \mathrm{pnA} \\
\left(7.2 \times 10^{11} \mathrm{pps}\right)\end{array}$} & $6.2 \times 10^{7}$ & $5.4 \times 10^{8}$ & $4.7 \times 10^{8}$ \\
\hline${ }^{34} \mathrm{Ar}(7+) 844.5 \mathrm{~ms}$ & & $1.4 \times 10^{6}$ & $1.2 \times 10^{7}$ & $1.1 \times 10^{7}$ \\
\hline${ }^{33} \mathrm{Ar}(8+) 173 \mathrm{~ms}$ & & $1.8 \times 10^{4}$ & $1.6 \times 10^{5}$ & $1.4 \times 10^{5}$ \\
\hline${ }^{32} \mathrm{Ar}(8+) 98 \mathrm{~ms}$ & & $1.0 \times 10^{2}$ & $8.7 \times 10^{2}$ & $7.8 \times 10^{2}$ \\
\hline${ }^{19} \mathrm{Ne}(5+) 17.22 \mathrm{~s}$ & \multirow{3}{*}{$\begin{array}{c}20 \mathrm{Ne}, 96 \mathrm{~A} \mathrm{MeV} \\
208 \mathrm{pnA} \\
\left(1.3 \times 10^{12} \mathrm{pps}\right)\end{array}$} & $5.0 \times 10^{7}$ & $2.4 \times 10^{8}$ & $3.8 \times 10^{8}$ \\
\hline $18 \mathrm{Ne}(5+) 1.67 \mathrm{~s}$ & & $3.1 \times 10^{6}$ & $1.5 \times 10^{7}$ & $2.3 \times 10^{7}$ \\
\hline $17 \mathrm{Ne}(5+) 109 \mathrm{~ms}$ & & $3.1 \times 10^{4}$ & $1.5 \times 10^{5}$ & $2.3 \times 10^{5}$ \\
\hline $8 \mathrm{He}(1+) 119 \mathrm{~ms}$ & $\begin{array}{c}{ }^{13} \mathrm{C}, 75 \mathrm{~A} \mathrm{MeV} \\
421 \mathrm{pnA} \\
\left(2.6 \times 10^{12} \mathrm{pps}\right)\end{array}$ & $2.1 \times 10^{5}$ & $5.0 \times 10^{5}$ & $1.5 \times 10^{6}$ \\
\hline
\end{tabular}

\section{REFERENCES}

* Invited talk presented at the International Symposium of Physics of Unstable Nuclei, Niigata, Japan, 31 October - 3 November 1994

1. E. Hagebø et al., Nucl. Instr. Meth. Phys. Res. B70 (1992) 165.

2. T.J.M. Symons et al., Phys. Rev. Lett. 42 (1979) 40,

G.D. Westfall et al., Phys. Rev. Lett. 43 (1979) 1859.

3. I. Tanihata et al., Phys. Lett. 160B (1985) 380 and Phys Rev. Lett. 55 (1985) 2676.

4. W. Mittig, GANIL preprint P 94 05, to be published in Proc. of Int. Workshop on RNB prod. by Fragm. Sep. Techniques, Varna Bulgaria, 1993

5. P. Van Duppen et al., Nucl. Intr. Meth. Phys. Res. B70 (1992) 393.

6. R. Anne et al., Proc. Part. Acc. Conf. APS, Washington, USA (1993) 1792.

7. G. Auger et al., Nucl. Instr. Meth Phys. Res. A350 (1994) 235.

8. M. Fujioka and Y. Arai, Nucl. Instr. Meth. 186 (1981) 409.

9. P. Sortais et al., Rev. Sci. Instr. 61 (1990) 288.

10. P. Sortais et al., Proc. 11 th Int. Workshop on ECRIS, KVI - report 996 (1993) 9.7. 